\title{
Electrochemical Tests to Evaluate the Stability of the Anodic Films on Dental Implants
}

\author{
C. E. B. Marino ${ }^{1}$ and L. H. Mascaro ${ }^{2}$ \\ ${ }^{1}$ Laboratório de Materiais Bicompativeis, Departamento de Engenharia Mecânica, Universidade Federal do Paraná, \\ Jardim das Américas, CP 19081, 81531-990 Curitiba, PR, Brazil \\ ${ }^{2}$ Laboratório Interdisciplinar de Cerâmica, Departamento de Química, Universidade Federal de São Carlos, Rod. Washungton Luiz, \\ km 235, CP 676, 13565-905 São Carlos, SP, Brazil \\ Correspondence should be addressed to C. E. B. Marino, claudiamarino@ufscar.br
}

Received 12 January 2011; Revised 12 April 2011; Accepted 2 May 2011

Academic Editor: Davood Nematollahi

Copyright (C) 2011 C. E. B. Marino and L. H. Mascaro. This is an open access article distributed under the Creative Commons Attribution License, which permits unrestricted use, distribution, and reproduction in any medium, provided the original work is properly cited.

\begin{abstract}
The stability of anodic films potentiodynamically grown on titanium, titanium-grade 2, and Ti6Al4V alloy was studied in a simulated physiological electrolyte, up to $8.0 \mathrm{~V}$, and at room temperature to determine the corrosion resistance levels of dental implants. In PBS (phosphate buffer saline) solution, thin titanium oxide films protect the surface of the Ti6\%Al4\%V alloy up to $6.0 \mathrm{~V}$, pure Ti up to $8.0 \mathrm{~V}$, and Ti-grade 2 up to $1.5 \mathrm{~V}$. At more positive potentials, localized corrosion starts to occur possibly due to the alloy elements (Ti6Al4V-V and $\mathrm{Al}$ ) and variable levels of interstitials (Ti-grade 2: $\mathrm{C}, \mathrm{N}$, and Fe, mainly). When the biomaterials were submitted to open-circuit conditions, in artificial saliva, the worst corrosion resistance was observed in dental implant (Ti-grade 2), according to the open-circuit potential values and reconstruction rate analysis of these oxide films. The XPS spectra revealed $\mathrm{TiO}_{2}$ oxide as the main phase in the barrier oxide film coating the dental implant.
\end{abstract}

\section{Introduction}

The use of titanium as a material for surgical purposes began around the 1960s. For this purpose, this material must not cause any adverse biological reaction in the body, and it must also be stable and retain its functional properties. Due to its attractive mechanical and chemical characteristics and its property of "biofixation" with the periprosthetic tissue, titanium is established as one of the major materials used for manufacturing orthopedic implants [1]. The excellent corrosion resistance of titanium and its alloys results from the formation of very stable, continuous, highly adherent, and protective oxide films on metal surfaces. Because titanium itself is highly reactive and has extremely high affinity for oxygen, these beneficial surface oxide films form spontaneously and instantly when fresh metal surfaces are exposed to air. The nature, composition, and thickness of the protective surface oxides on titanium alloys depend on environment conditions. Titanium is normally covered with a thin oxide film, which largely determines the surface properties of an implant [1]. The high corrosion resistance of titanium is due to the formation of these protective oxide films (thickness 1 to $4 \mathrm{~nm}$ ) [2], but body fluids contain chloride ions that can induce a breakdown of passive films on prostheses $[3,4]$. Corrosion and surface film dissolution are two mechanisms for introducing additional ions in the human body. Extensive release of metal ions from prosthesis can result in adverse biological reactions and can lead to mechanical failure of the device [5].

The thin oxide film, naturally formed on a titanium substrate, is responsible for the excellent biocompatibility of titanium implants. This fact occurs because of the low level of electronic conductivity, a thermodynamically stable state in the physiological media, besides high corrosion resistance [6]. Previous studies have described a variety of properties of anodic oxide films, for example, surface morphology, crystal structures, and corrosion resistance [7]. One way to change the surface characteristics of implants is varying the properties of the oxide films always present on Ti surfaces. Oxidized implants change the properties of the titanium implant and 
play an important role during the dynamic buildup of the osteointegration process $[1,8]$. Healy and Ducheyne [9] already investigated the superficial changes, stoichiometry, and absorbed surface species on titanium oxide during exposure to model physiological environments. As a result of these studies, it was observed that the oxide incorporates both $\mathrm{Ca}$ and $\mathrm{P}$ elements from the extra cellular fluid and that it increases in thickness as function of implantation time. Kuphasuk et al. [10] studied the electrochemical behavior of $\mathrm{Ti}$, Ti6Al4V, NiTi, and three other titanium alloys at $37^{\circ} \mathrm{C}$ in Ringer's solution. Electron diffraction patterns indicated that all titanium alloys were covered mainly with rutile-type oxide after corrosion tests, and the $\mathrm{Ti}$ and $\mathrm{Ti} 5 \mathrm{Al} 2.5 \mathrm{Fe}$ were the most resistant to corrosion. The study of the corrosion resistance in chloride media of Ti-based dental implants was investigated by Arslan et al. [11]. By the Tafel slopes and EIS Nyquist spectra, the galvanic corrosion was evaluated, and the Ti6Al4V/CoCr and Ti6Al4V/CrNi systems were to be similar corrosion behavior.

One of the problems associated with corrosion study of dental alloys is that the knowledge of the electrochemical environment of oral cavity is limited to simulating this media. The electrochemical properties of the oxide film and its long-term stability in biological environments play a decisive role for the biocompatibility of titanium implants [12-14].

A method of expanding the corrosion resistance of titanium into reducing environments is increasing the surface oxide film thickness by anodizing or thermal oxidation [1]. In the present work, the growth of the oxide and its stability in Ti, Ti-grade 2, and Ti6Al4V alloy were studied in physiological solutions at room temperature $\left(\sim 25^{\circ} \mathrm{C}\right)$ by electrochemical techniques. The titanium oxide characterization was made through X-ray photoelectron spectroscopy (XPS) and microstructural aspects by metallographic techniques.

\section{Experimental}

A conventional $250 \mathrm{~mL}$ three-electrode electrochemical cell was used. The working electrodes were $\mathrm{Ti6} \% \mathrm{Al} \% \mathrm{~V}$ $(6 \% \mathrm{~m} / \mathrm{m}$ and $4 \% \mathrm{~m} / \mathrm{m}$ of $\mathrm{Al}$ and $\mathrm{V}$, resp.) alloy rod (Titanium Industries-USA), pure Ti (Aldrich, 99.99\%), and Ti-grade 2 (dental screw [15]) giving an area of $\sim 1.26 \mathrm{~cm}^{2}, \sim 0.28 \mathrm{~cm}^{2}$ and $0.062 \mathrm{~cm}^{2}$, respectively, and were exposed to the electrolytes. Prior to the oxide growth, the electrodes were mechanically polished with silicon carbide paper of grade 600 and rinsed with distilled water. A platinum electrode was used as counterelectrode, and all potentials were measured against a saturated calomel electrode (SCE). The electrolytes were PBS solution (phosphate buffer saline-pH 7; $8.77 \mathrm{~g} \cdot \mathrm{L}^{-1} \mathrm{NaCl}, 3.58 \mathrm{~g} \cdot \mathrm{L}^{-1} \mathrm{Na}_{2} \mathrm{HPO}_{4}$, $1.36 \mathrm{~g} \cdot \mathrm{L}^{-1} \quad \mathrm{KH}_{2} \mathrm{PO}_{4}$ ) [16] for the growth of the oxides and artificial saliva $\left(\mathrm{pH} \quad 7 ; 0.4 \mathrm{~g} \cdot \mathrm{L}^{-1} \mathrm{NaCl}, 0.4 \mathrm{~g} \cdot \mathrm{L}^{-1}\right.$ $\mathrm{KCl}, 0.795 \mathrm{~g} \cdot \mathrm{L}^{-1} \quad \mathrm{CaCl}_{2} \cdot \mathrm{H}_{2} \mathrm{O}, 0.69 \mathrm{~g} \cdot \mathrm{L}^{-1} \quad \mathrm{NaH}_{2} \mathrm{PO}_{4} \cdot \mathrm{H}_{2} \mathrm{O}$, $0.005 \mathrm{~g} \cdot \mathrm{L}^{-1} \mathrm{Na}_{2} \mathrm{~S} \cdot 9 \mathrm{H}_{2} \mathrm{O}, 1.0 \mathrm{~g} \cdot \mathrm{L}^{-1}$ urea) [17] for the study of spontaneous dissolution process, at room temperature. All electrochemical measurements were carried out with a Microquimica-MQPG-01 electrochemical system. The initial

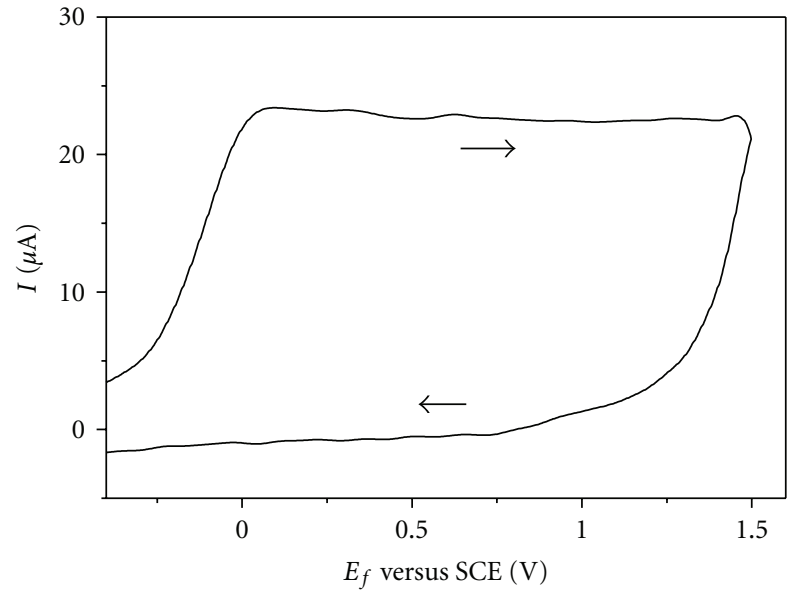

Figure 1: Cyclic voltammogram for Ti-grade 2 electrode in PBS solution at $50 \mathrm{mV} \cdot \mathrm{s}^{-1}$ and $25^{\circ} \mathrm{C}$.

$\left(E_{i}\right)$ and final $\left(E_{f}\right)$ potentials for the potentiodynamic growth at $50 \mathrm{mV} \cdot \mathrm{s}^{-1}$ of the oxides were $E_{i}=-1.0 \mathrm{~V}$ and $E_{f}=1.0-8.0 \mathrm{~V}$ (versus SCE) range. The electrodes were polished and the oxides potentiodynamically grown up to $E_{f}$, where the potential was held until a steady current was reached. Therefore, the circuit was open and the variation of potential with time (dissolution process) was analyzed for the $\mathrm{Ti}$ and its alloys covered with oxide electrodes, in artificial saliva solution. So, the stability of the anodic oxide in artificial saliva was studied. Finally, the anodic scan was repeated, in PBS solution, in order to obtain the potentiodynamic profile for the regrowth of any oxide that eventually had been dissolved [2]. The nature of the anodic oxides was investigated by X-ray photoelectron spectroscopy (XPS) using a Kratos Analytical XSAM HS Spectrometer having $\mathrm{Mg} \mathrm{K} \alpha(h v=1253.6 \mathrm{eV})$, X-ray source with power given by the emission of $15 \mathrm{~mA}$ at a voltage of $15 \mathrm{kV}$. The high-resolution spectra were obtained with analyzer energy of $20 \mathrm{eV}$. The binding energies were referred to the carbon $1 \mathrm{~s}$ line, set at $284.8 \mathrm{eV}$. A least-square routine was used for the fitting of the peaks.

\section{Results and Discussion}

3.1. Anodic Growth and Stability of the Oxides. Cyclic voltammetry was used to characterize the pure Ti system, varying $E_{f}$ between $1.0 \mathrm{~V}$ and $8.0 \mathrm{~V}$. This potential range was chosen because the corrosion process starts at potentials higher than 6.0 V, for Ti6Al4V alloy, in PBS solution $[18,19]$, and higher than $1.5 \mathrm{~V}$, for Ti-grade 2, in the same solution, as will be discussed. The voltammogram shown in Figure 1 indicates that the Ti-grade 2 has a similar anodic transformation when compared with pure $\mathrm{Ti}$ [2]. This fact is possible due to the growth of a uniform oxide film, mainly $\mathrm{TiO}_{2}$. However, the potential sweep in the positive direction shows an anodic current starting with $-0.55 \mathrm{~V}$ for the titanium electrode [2] and $-0.15 \mathrm{~V}$ for Ti-grade 2 electrode. The delay in starting potential oxide growth, in the case of dental implant (Tigrade 2), could be explained by the presence of impurities 


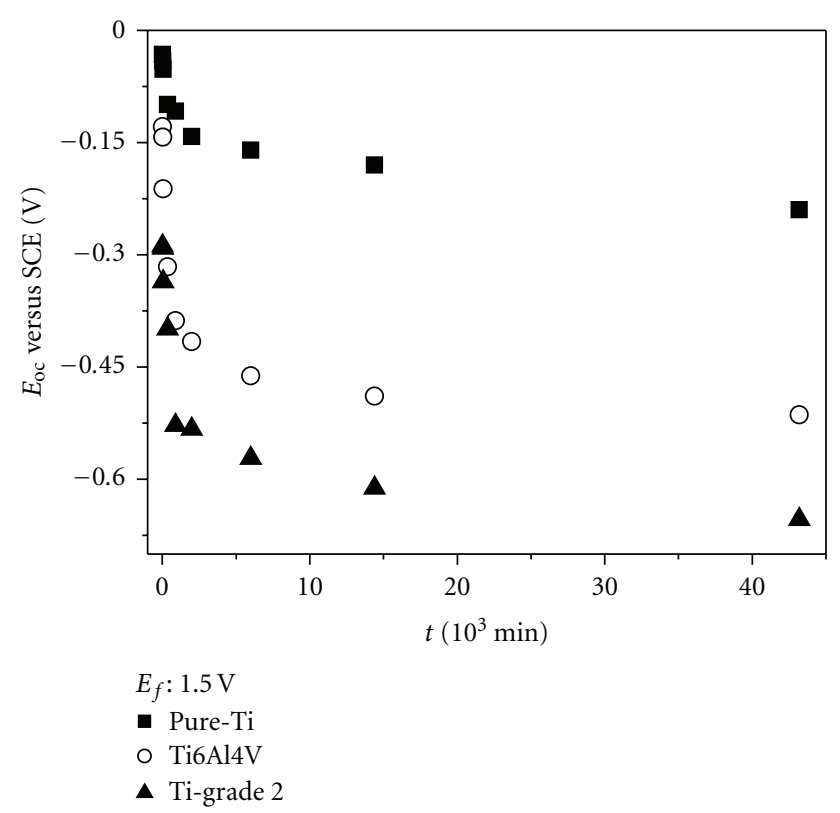

FIGURE 2: Open-circuit potentials as a function of immersion time, in artificial saliva, for Ti pure, Ti6Al4V, and Ti-grade 2 covered with oxide films potentiodynamically grown up to $1.5 \mathrm{~V}$, in PBS solution.

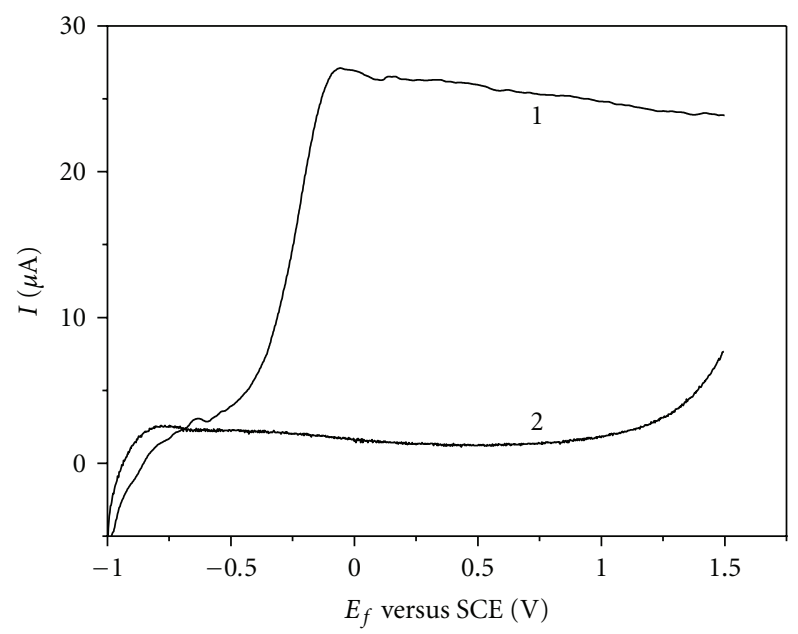

FIGURE 3: Voltammetric profiles for the growth (curve 1) and regrowth (curve 2) of the oxide film grown on Ti-grade 2 up to $E_{f}$ $1.5 \mathrm{~V}$, in PBS solution, at $50 \mathrm{mV} \cdot \mathrm{s}^{-1}$ and $25^{\circ} \mathrm{C}$.

and/or variable levels of interstitials into the biomaterial that causes differences in their stability. These hypotheses will be analyzed by microstructural and by chemical composition tests. With an increase in the potential, the current density remains almost constant indicating a process of thickening of the anodic surface film. After the growth and aging of the oxide films up to different potentials $\left(E_{f}\right)$, the circuit was open and the potential decaying was measured, to analyze the spontaneous dissolution of these different oxide films. From this, the immersion time in artificial saliva was varied. When the open-circuit potential (OCP) became stationary, a new potential sweep, from -1.0 to $1.5 \mathrm{~V}$, was carried out to regrow

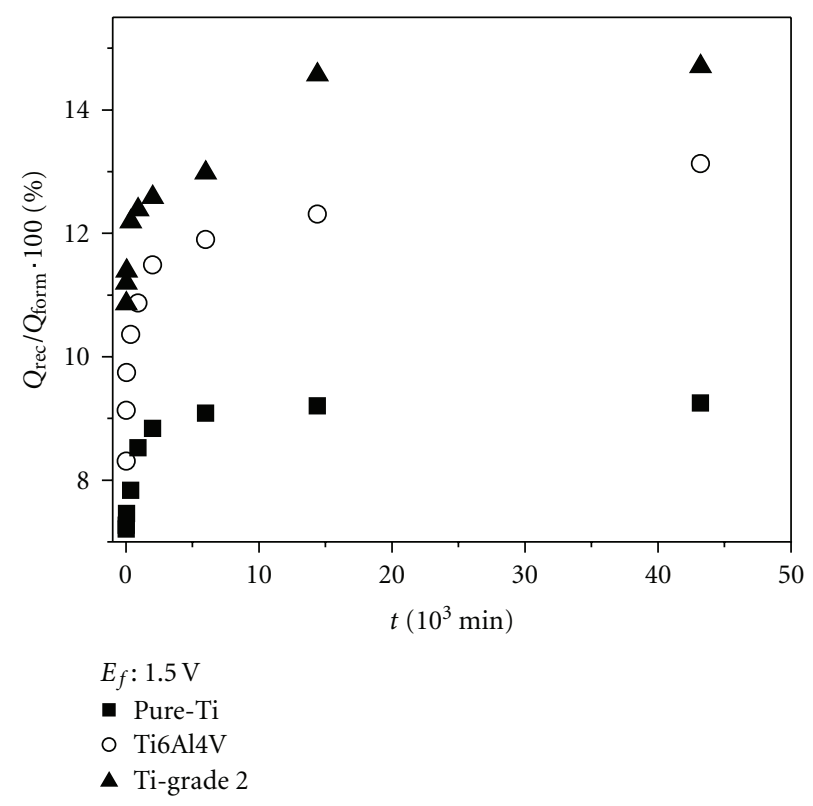

FIGURE 4: Oxide film reconstruction rate (RR\%) as a function of immersion time, in saliva artificial, for Ti pure, Ti6Al4V alloy, and Ti-grade 2 electrodes covered with oxide films potentiodynamically grown up to $1.5 \mathrm{~V}$, in PBS solution.

any film that might have been dissolved. In acid solutions, Blackwood et al. [20] proposed that the dissolution reaction of open-circuit breakdown of passive film on $\mathrm{Ti}$ might be written as

$$
\mathrm{TiO}_{2}+\mathrm{H}_{2} \mathrm{O}+\mathrm{H}^{+} \longrightarrow \mathrm{Ti}(\mathrm{OH})_{3}^{+}
$$

Following the OCP evolution, it is possible to understand the general interactions and the spontaneous dissolution of oxide grown up to $1.5 \mathrm{~V}$ that takes place at the biomaterials surface. The open-circuit potential $\left(E_{\mathrm{oc}}\right)$ of the pure Ti, Tigrade 2, and Ti6Al4V alloy in artificial saliva is shown in Figure 2. In artificial saliva, the $E_{\mathrm{oc}}$ of all biomaterials, was stabilized after a week at values between $-0.63 \mathrm{~V}$ and $-0.24 \mathrm{~V}$ versus SCE. The worst corrosion resistance was observed in the dental implant (Ti-grade 2) according to lower $E_{\mathrm{oc}}$ and higher reconstruction rate (see below).

The anodic charges related to the formation $\left(Q_{f}\right)$ and reconstruction $\left(Q_{\text {rec }}\right)$ of the anodic oxide allowed for an evaluation of the magnitude of these processes, in PBS solution. These charges were obtained considering the areas under the anodic sweeps before and after OCP measurements in artificial saliva, which are integrated between -1.0 and $1.5 \mathrm{~V}$. It means that the amount of current consumed while the electrochemical dissolution of the oxide film during $E_{\mathrm{oc}}$ was integrated. Figure 3 shows a typical valve metal behavior for the Ti-grade 2, and its anodic oxide grows according to the high-field model [2].

The oxide film reconstruction rate $(\mathrm{RR}$, expressed as a percentage) is defined as being equal to the ratio between the $Q_{\text {rec }}$ and the $Q_{f}[2]$, and these anodic charges were obtained by integration of the corresponding $I$ versus $E$ curves. Figure 4 shows the dependence of the reconstruction rate 


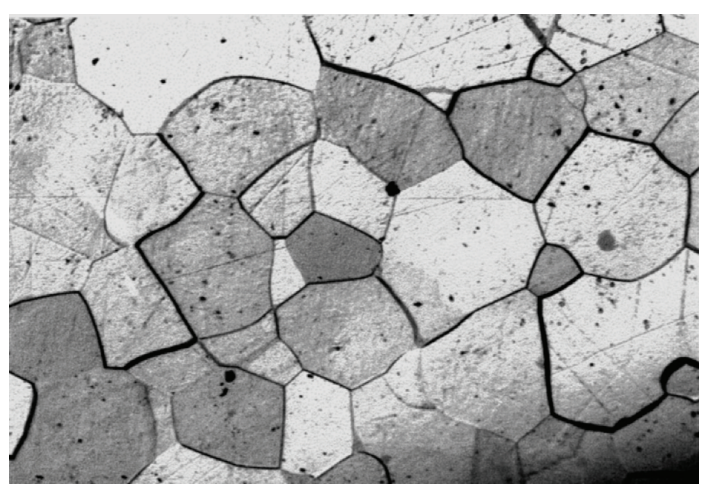

(a)

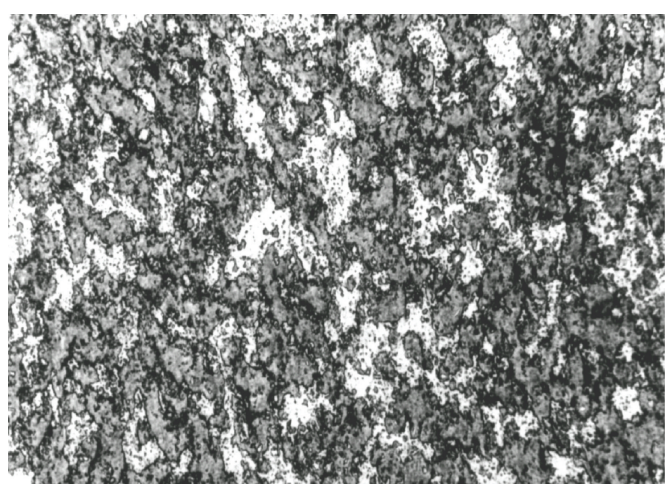

(b)

Figure 5: Photomicrographs of the Ti (a) and the dental implant, Ti-grade 2 (b), surfaces etched with the Kroll reagent (200x).

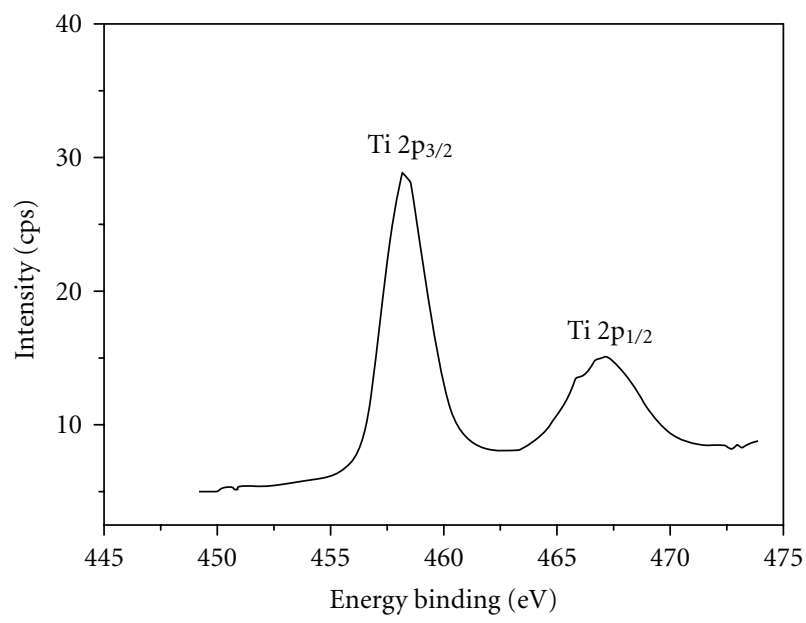

FIGURE 6: Ti 2p XPS spectrum for the oxide film potentiodynamically grown on the dental implant, Ti-grade 2, in PBS solution.

(RR\%) on immersion time in artificial saliva. The RR values of oxides increase with immersion time and stabilize in 15\% Ti-grade 2, 13\% Ti6Al4V alloy, and 9\% pure Ti, after around a week, in artificial saliva. So, the dissolution process of these oxide films is more effective in the dental implant (Ti-grade 2) in this physiological media as previously observed by potential sweep. Species from the electrolytic solution can be incorporated into the oxide matrix [20] leading to changes in its mechanical properties. The oxides have a natural level of internal stress, but the presence of incorporated foreign species affects directly the PillingBedworth ratio (ratio between the oxide molar volume and the metal molar volume), inducing alterations in the internal stress that may cause the rupture of the protecting oxide film [21].

In agreement with what was previously stated, the impedance data previously described $[11,19,22]$ show the influence of the $\mathrm{Cl}^{-}$presence on the passive oxide stability. By completing this research, we already presented the characterization of these anodic films by electrochemical impedance [19]. The impedance response indicated the existence of a thin oxide film on dental implant that suffers a dissolution process during different immersion times. This fact was confirmed by resistive and capacitive behaviors, as the corrosion resistance of the Ti-grade 2 is less than pure Ti. The resistance of the passive film on Ti-grade 2 decreased when the exposure time is increased, due to the oxide breakdown followed by a dissolution process. The capacitive behavior indicated the presence of a uniform and thin oxide on the implant surface. The influence of chloride media on the stability of anodic films on titanium-based materials by voltammetric studies has been presented by our research members [18].

An average value of $2.5 \mathrm{~nm} \mathrm{~V}^{-1}$ was obtained for the anodization rate in pure $\mathrm{Ti}$ oxides [2]. In the case of $\mathrm{Ti}$ grade 2 , the anodization rate is $2.1 \mathrm{~nm} \mathrm{~V}^{-1}$ indicating a lower protect layer to a fixed final potential. This result is according to the magnitude of the reconstruction rate obtained to the dental implant in artificial saliva (see Figure 4). This worst corrosion resistance could be related to the presence of contaminants and impurities and/or to the microstructural variations that occur after thermal and conformational treatments. Therefore, the dental implant becomes more vulnerable to the corrosion processes [23].

In the corrosion-dissolution process, the presence of ions released from the implant could affect the tissue-bone material interactions that cause damage in the osteointegration process resulting from the looseness of implant. Marino and Mascaro [19] have found that the spontaneous dissolution rate of $\mathrm{TiO}_{2}$ in sulfuric acid solutions, at various $\mathrm{pHs}$, is first order with respect to proton concentration. Thus, we proposed that the oxide hydrolysis might be written as reaction (1). Therefore, a very slow chemical dissolution could be associated with the release of $\mathrm{Ti}(\mathrm{OH})_{3}{ }^{+}$ions and other unstable elements in oxide matrix.

\section{Microstructural Analysis}

The electrochemical results suggest that the corrosion resistance decreases with increasing levels of impurities. Therefore, the microstructural analysis could show the natural tendency of biomaterial corrosion resistance. 


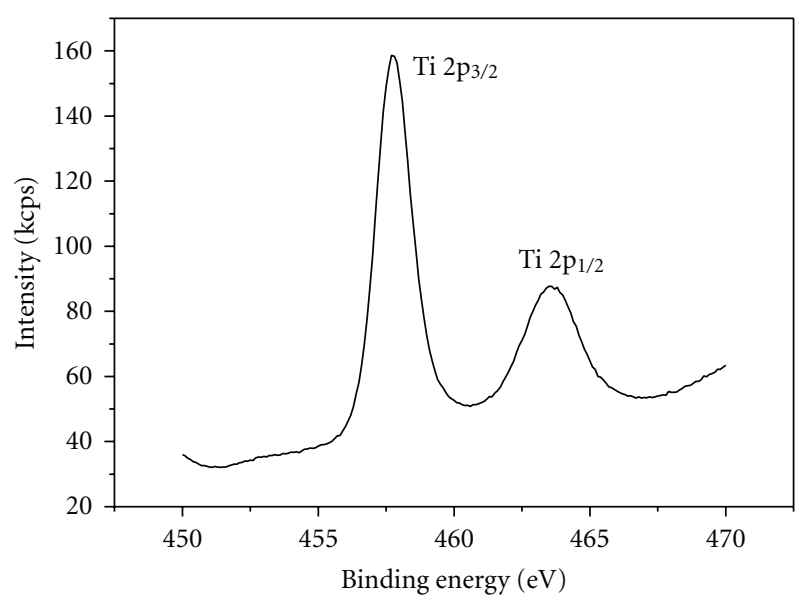

(a)

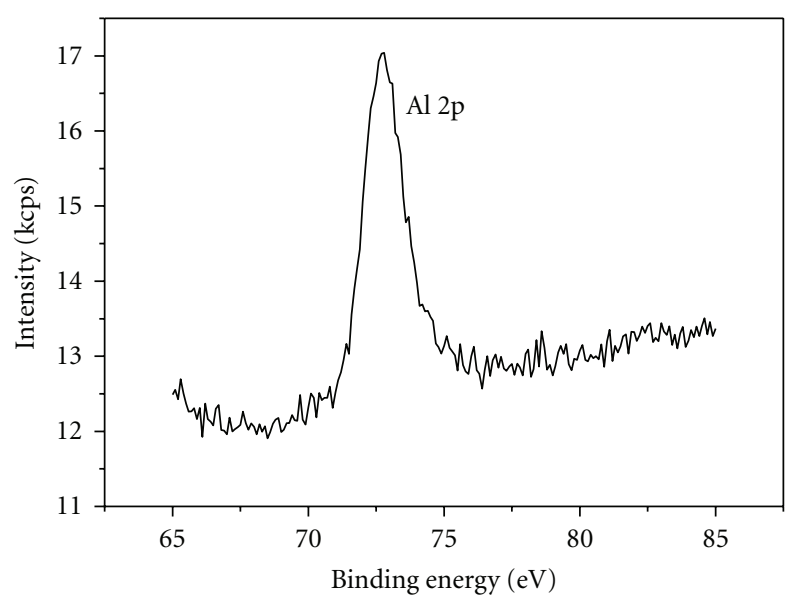

(b)

Figure 7: (a) Ti 2p and (b) Al 2p XPS spectra for the oxide film potentiodynamically grown on the Ti6Al4V alloy, in PBS solution.

Information about the chemical composition and structural aspects of these biomaterials is essential to the knowledge of its behavior and stability in aggressive media, such as body fluids $[24,25]$. The microstructures of the $\mathrm{Ti}$, Ti-grade 2 and Ti6Al4V alloy were analyzed after mirror polishing and etching their surfaces with a Kroll solution $\left(6: 1: 1000 \mathrm{v} / \mathrm{v} / \mathrm{v} \mathrm{HNO}_{3}: \mathrm{HF}: \mathrm{H}_{2} \mathrm{O}\right)$ for approximately $15 \mathrm{~s}$. The adherent oxide film on the surface of $\mathrm{Ti}$ and $\mathrm{Ti}$ alloys requires strong etchings to minimize the staining problems that might obscure the microstructure.

Titanium has hexagonal close-packed atomic lattice structure ( $\alpha$ titanium-phase) which is stable up to $882^{\circ} \mathrm{C}$, and it transforms into a face-centered cubic structure $(\beta$ titanium phase) above this temperature. Pure titanium is a soft and ductile metal, but the impurities or addition of alloying elements makes it harder and less ductile. In the Ti6Al4V alloy, the aluminum stabilizes the $\alpha$ phase and the vanadium stabilizes $\beta$ phase. These alloying elements are known to increase the mechanical properties of titanium [1]. The addition of the elements aluminum and vanadium refined the grain size of the alloy [18]. The pure titanium microstructure shows a satisfactory homogeneity, indicating good corrosion resistance [20] (see Figure 5(a)).

Figure 5(b) shows the dental implant (Ti-grade 2) microstructure, in which the superficial deposition of the attack product is not uniform. This fact occurs because of the different expositions of the crystallographic planes, and each grain has its own crystalline orientation in relation to the attack plane. Comparing the pure $\mathrm{Ti}$ and Ti-grade 2 microstructures, it is possible to observe some important alterations. The Ti-grade 2 microstructure presents nonuniform grains. The elongated grains indicate that the material was deformed, without recrystallization, and sustain some strain hardening (tensioned regions) (see Figure 5). Also, notice that dark regions (more intensive attack) are in major proportions than clear regions, which confirms the partially strain-hardened material. These strain-hardened areas are anodic regions in corrosion process.
The difference in Ti purity levels and its fabrication characterizes the kinds of Ti grade 1, 2, 3, and 4 and their mechanical and corrosion resistance properties [1]. Thus, the microstructural analysis sustained that the lowest corrosion resistance of Ti-grade 2 is due to the levels of interstitials and other impurities, a fact that damages the osteointegration process [3].

\section{Characterization of Oxide Film}

The characterization of the passive oxide film coating Tigrade 2 implant was done by X-ray photoelectron spectroscopy (XPS). The potential value was chosen in order to have passive films grown up to $1.5 \mathrm{~V}(\sim 40 \AA$ thick, according to previous results [2]), in PBS solution. Figure 6 presents the XPS spectrum for Ti $2 p$ electron to the dental implant covered with titanium oxide film obtained in phosphate buffer solution. The spectrum shows the doublet referent to Ti $2 p$ that consists at the peaks: Ti $2 p_{1 / 2}$ and Ti $2 p_{3 / 2}$. These subindices indicate the level of the element in spectroscopic analysis. The doublet was determined by the Ti $2 \mathrm{p}_{3 / 2}$ peak with binding energy around $459.0 \mathrm{eV}$, which corresponds to the $\mathrm{Ti}^{4+}$ signal [26]. This indicates that $\mathrm{TiO}_{2}$ is the main oxide present in the passive film, consistent with results reported previously using different approaches $[18,27]$.

When the surface analyzed was Ti6Al4V/oxide, the effects of alloying elements in passive films were examined by X-ray photoelectron spectroscopy (Figure 7). The peaks indicate that $\mathrm{TiO}_{2}\left(\mathrm{Ti}^{4+}\right)$ is the major surface component for both $\mathrm{Ti}$ - grade 2 and Ti6Al4V alloy samples. The peak positions for $\mathrm{TiO}_{2}$ were consistent with binding energy shifts expected for titanium in combination with oxygen in the form of $\mathrm{TiO}_{2}$ $[21,27]$.

The high-resolution $\mathrm{Al} 2 \mathrm{p}$ spectrum results for the Ti6Al4V alloy sample are shown in Figure 7(b). The presence of elemental aluminum metal can be verified $\left(\mathrm{Al}^{0}\right)$ at binding energy at $72.5 \mathrm{eV}$. Some authors $[27,28]$ reported the measured binding energies of surface $\mathrm{Al}$ and $\mathrm{V}$ to be 
consistent with oxides such as $\mathrm{Al}_{2} \mathrm{O}_{3}$ and $\mathrm{V}_{2} \mathrm{O}_{5}$ or even $\mathrm{Al}$ and $\mathrm{V}$ existing as ions at interstitial or substitutional sites in the $\mathrm{Ti}$ oxide matrix. In the present work, the thin oxide film on the Ti6Al4V alloy could be a "solid solution" of titanium oxide $\left(\mathrm{TiO}_{2}\right)$ that contains dissolved aluminum and vanadium. In addition, by the chemical environment analysis of $\mathrm{Al}$, which indicated the absence of $\mathrm{O}$ atoms around it, and considering the values of ionic radius of these alloy elements, it was possible to suppose that both $\mathrm{Al}$ and $\mathrm{V}$ would be present as ions at interstitial sites in the Ti oxide matrix. The vanadium alloy element was not detected by XPS analysis but this element could be present in the oxide with concentrations lower than 0.1 at. $\%$ which represents the detection limit of the XPS technique.

Besides, the total XPS spectrum revealed Fe contaminant present in the Ti-grade 2 oxide matrix. The binding energy of Fe $2 \mathrm{p}$ peak is around $715.0 \mathrm{eV}$, and its atomic percentage is $1.8 \%$ which could affect its properties. For pure $\mathrm{Ti}$ and Ti6Al4V alloy, the absence of Fe was observed [28]. Finally, it was described that high levels of interstitials in dental implants affected the corrosion resistance and the osteointegration process $[3,5]$.

\section{Conclusions}

In this work, it was shown that thin titanium oxide films grown potentiodynamically protect the Ti-grade 2 surfaces up to $1.5 \mathrm{~V}$ in artificial saliva, at room temperature. At more positive potentials, corrosion processes start to occur. This can be explained due to the presence of variable levels of interstitials (impurities) in Ti-grade 2 screws that could decrease their corrosion resistance. The results were confirmed by metallographic and XPS data. The XPS spectra revealed the $\mathrm{TiO}_{2}$ as the most important phase in the passive film, besides the presence of Fe traces that modify the dental implant properties. Therefore, Ti-grade 2 screws showed an increase of heterogeneity regarding its chemical composition and microstructural aspects when compared with pure Ti. These changes cause susceptibility to corrosion processes, in body fluids. So, the presence of oxide films coating the implant surface is a good pretreatment against corrosion processes, and it also increases the durability of these implants.

\section{Acknowledgments}

The authors are grateful to the Conselho Nacional para $o$ Desenvolvimento Cientifico e Tecnológico $(\mathrm{CNPq})$ for the scholarship and to the Fundação Araucária for the financial support.

\section{References}

[1] K. J. Bundy, "Corrosion and other electrochemical aspects of biomaterials," Critical Reviews in Biomedical Engineering, vol. 22, no. 3-4, pp. 139-251, 1994.

[2] C. E. B. Marino, E. M. Oliviera, R. C. Rocha-Filho, and S. R. Biaggio, "On the stability of thin-anodic-oxide films of titanium in acid phosphoric media," Corrosion Science, vol. 43, no. 8, pp. 1465-1476, 2001.

[3] H. L. Myshin and J. P. Wiens, "Factors affecting soft tissue around dental implants: a review of the literature," The Journal of Prosthetic Dentistry, vol. 94, no. 5, pp. 440-444, 2005.

[4] S. Virtanen, I. Milošev, E. Gomez-Barrena, R. Trebše, J. Salo, and Y. T. Konttinen, "Special modes of corrosion under physiological and simulated physiological conditions," Acta Biomaterialia, vol. 4, no. 3, pp. 468-476, 2008.

[5] C.-H. Chung et al., "Electrochemical behavior of dental implant system before and after clinical use," Transactions of Nonferrous Metals Society of China, vol. 19, pp. 846-851, 2009.

[6] Y. T. Sul, C. B. Johansson, S. Petronis et al., "Characteristics of the surface oxides on turned and electrochemically oxidized pure titanium implants up to dielectric breakdown: the oxide thickness, micropore configurations, surface roughness, crystal structure and chemical composition," Biomaterials, vol. 23, no. 2, pp. 491-501, 2002.

[7] M. Metikos and R. Babic, "Some aspects in designing passive alloys with an enhanced corrosion resistance," Corrosion Science, vol. 51, no. 1, pp. 70-75, 2009.

[8] K. Lee, H.-C. Choe, B.-H. Kim, and Y.-M. Ko, "The biocompatibility of HA thin films deposition on anodized titanium alloys," Surface and Coatins Technology, vol. 205, supplement 1, pp. S267-S270, 2010.

[9] K. E. Healy and P. Ducheyne, "Hydration and preferential molecular adsorption on titanium in vitro," Biomaterials, vol. 13, no. 8, pp. 553-561, 1992.

[10] C. Kuphasuk, Y. Oshida, C. J. Andres, S. T. Hovijitra, M. T. Barco, and D. T. Brown, "Electrochemical corrosion of titanium and titanium-based alloys," The Journal of Prosthetic Dentistry, vol. 85, no. 2, pp. 195-202, 2001.

[11] H. Arslan, H. Çelikkan, N. Örnek, O. Ozan, A. E. Ersoy, and M. L. Aksu, "Galvanic corrosion of titanium-based dental implant materials," Journal of Applied Electrochemistry, vol. 38, no. 6, pp. 853-859, 2008.

[12] M. Songür, H. Çelikkan, F. Gökmeşe, S. A. Şimşek, N. Ş. Altun, and M. L. Aksu, "Electrochemical corrosion properties of metal alloys used in orthopaedic implants," Journal of Applied Electrochemistry, vol. 39, no. 8, pp. 1259-1265, 2009.

[13] C. Fleck and D. Eifler, "Corrosion, fatigue and corrosion fatigue behavior of metal implant materials, especially titanium alloys," International Journal of Fatigue, vol. 32, no. 6, pp. 929-935, 2010.

[14] D. Upadhyay, M. A. Panchal, R. S. Dubey, and V. K. Srivastava, "Corrosion of alloys used in dentistry: a review," Materials Science and Engineering A, vol. 432, no. 1-2, pp. 1-11, 2006.

[15] ASTM F67-95, "Standard Specification for unalloyed titanium for surgical implants applications".

[16] J. Y. Gal, Y. Foret, and M. A. Yadzi, "About a synthetic saliva for in vitro studies," Talanta, vol. 53, no. 6, pp. 1103-1115, 2001.

[17] T. Fusayama, T. Katayori, and S. Nomoro, "Corrosion of gold and amalgam placed in contact with each other," Journal of Dental Research, vol. 42, pp. 1183-1197, 1963.

[18] C. E. B. Marino, N. Bocchi, R. C. Rocha-Filho, and S. R. Biaggio, "Voltammetric stability of anodic films on the Ti6Al4V alloy in chloride medium," Electrochimica Acta, vol. 51, no. 28, pp. 6580-6583, 2006.

[19] C. E. B. Marino and L. H. Mascaro, "EIS characterization of a Ti-dental implant in artificial saliva media: dissolution process of the oxide barrier," Journal of Electroanalytical Chemistry, vol. 568, no. 1-2, pp. 115-120, 2004.

[20] D. J. Blackwood, L. M. Peter, and D. E. Williams, "Stability and open circuit breakdown of the passive oxide film on 
titanium," Electrochimica Acta, vol. 33, no. 8, pp. 1143-1149, 1988.

[21] C. E. B. Marino, P. A. P. Nascente, N. Bocchi, R. C. RochaFilho, and S. R. Biaggio, "XPS characterization of anodic titanium oxide films grown in phosphate buffer solutions," Thin Solid Films, vol. 468, no. 1-2, pp. 109-112, 2004.

[22] V. A. Alves, R. Q. Reis, I. C. B. Santos et al., "In situ impedance spectroscopy study of the electrochemical corrosion of $\mathrm{Ti}$ and Ti-6Al-4V in simulated body fluid at $25^{\circ} \mathrm{C}$ and $37^{\circ} \mathrm{C}$," Corrosion Science, vol. 51, no. 10, pp. 2473-2482, 2009.

[23] C. V. Vidal and A. I. Muñoz, "Electrochemical characterisation of biomedical alloys for surgical implants in simulated body fluids," Corrosion Science, vol. 50, no. 7, pp. 1954-1961, 2008.

[24] I. Milosev, M. Metikos, and H. H. Strehblow, "Passive film on orthopaedic TiAlV alloy formed in physiological solution investigated by X-ray photoelectron spectroscopy," Biomaterials, vol. 21, no. 20, pp. 2103-2113, 2000.

[25] N. Zaveri, M. Mahapatra, A. Deceuster, Y. Peng, L. Li, and A. Zhou, "Corrosion resistance of pulsed laser-treated Ti-6Al-4V implant in simulated biofluids," Electrochimica Acta, vol. 53, no. 15, pp. 5022-5032, 2008.

[26] J. F. Moulder, P. E. Stickle, P. E. Sobol, and K. D. Bomben, Handbook of X-Ray Photoelectron Spectroscopy, Perkin-Elmer Corporation, Waltham, Mass, USA, 1992.

[27] B.-S. Kang, Y. T. Sul, SE. J. Oh, H. J. Lee, and T. Albrektsson, "XPS, AES and SEM analysis of recent dental implants," Acta Biomaterialia, vol. 5, no. 6, pp. 2222-2229, 2009.

[28] K. Bordji, J. Y. Jozeau, D. Mainard et al., "Cytocompatibility of Ti6Al4V and Ti5Al2.5Fe alloys according to three surface treatments, using human fibroblasts and osteoblasts," Biomaterials, vol. 17, no. 9, pp. 929-940, 1996. 


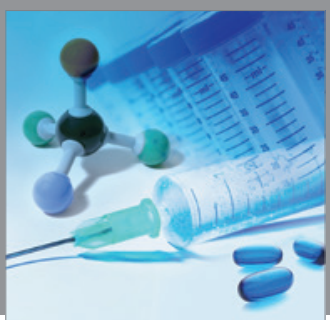

International Journal of

Medicinal Chemistry

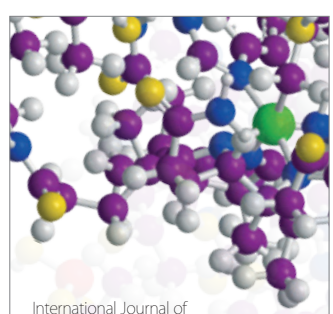

Carbohydrate Chemistry

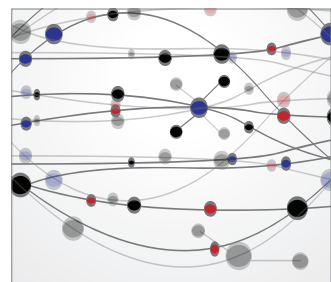

The Scientific World Journal
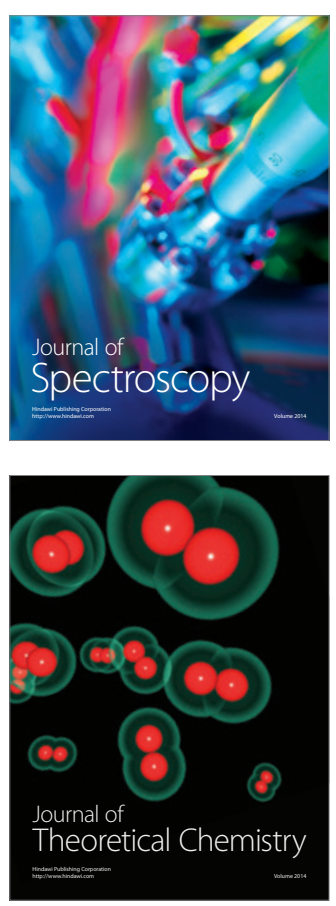
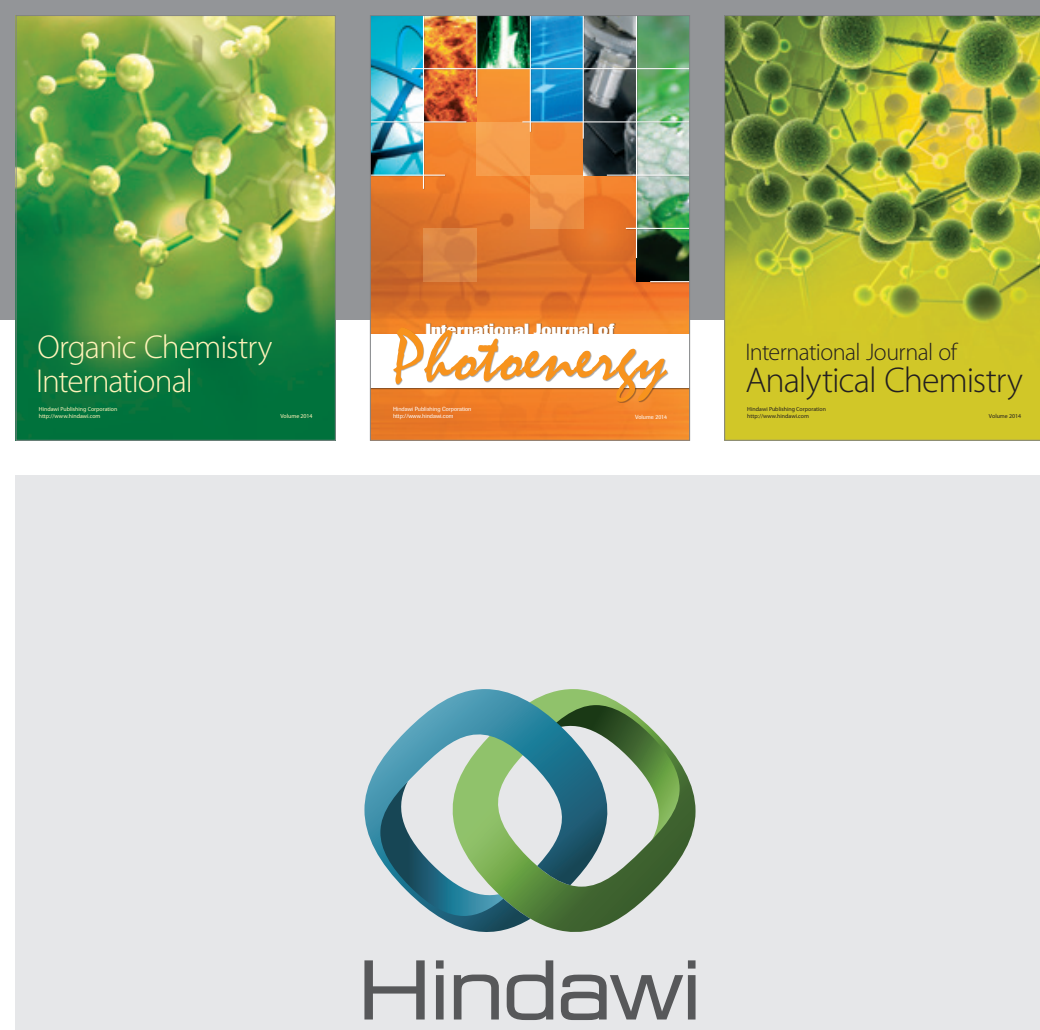

Submit your manuscripts at

http://www.hindawi.com
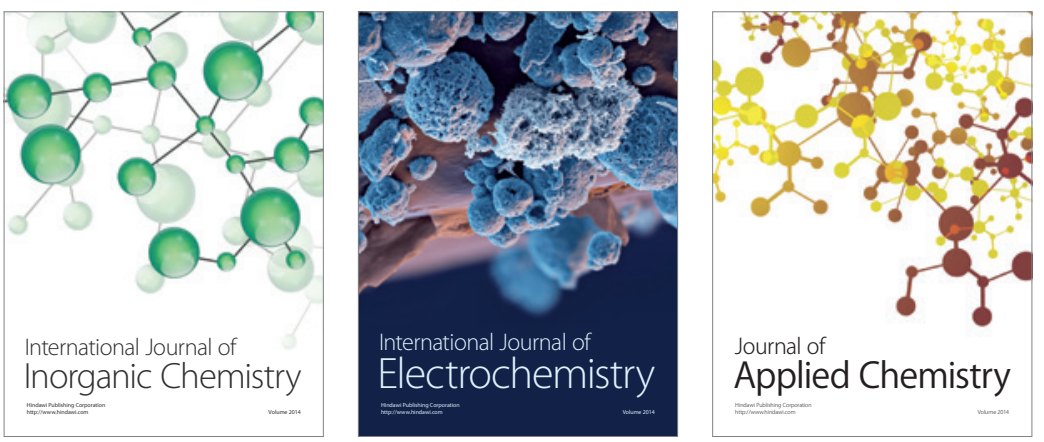

Journal of

Applied Chemistry
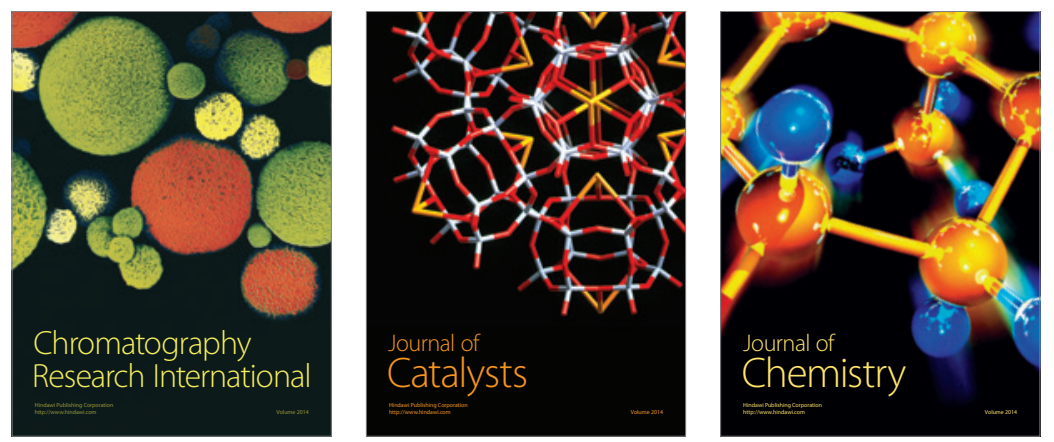
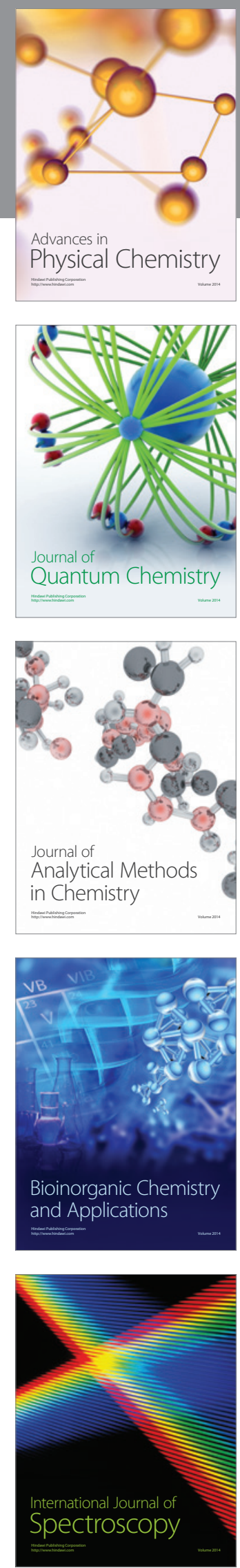